Research Article

\title{
International Immigration Policy and Evaluating the impacts of Immigration
}

\author{
Debolin Das $^{1 *}$, Farha Sultana ${ }^{2}$, Monisha Das ${ }^{3}$ \\ ${ }^{1}$ Department of History, Jahangirnagar University, Savar, Dhaka, Bangladesh. \\ ${ }^{2,3}$ Department of Management, Rangamati Science and Technology University, Rangamati, Bangladesh.
}

\begin{abstract}
:
Over the past three decades, new anti-immigration policies and laws have issued to address the migration of undocumented and illicit immigrants. This article will show a direct relationship between immigration policies and their effects. In addition, as a result of these policies, undocumented immigrants were impacted by mental health outcomes, including depression, anxiety, post-traumatic stress disorder, uncertain future, poor lifestyle, and unstable economic life. Even international immigration policy has serious limitations, particularly when viewed from an economic perspective. Some shortcomings arise from faulty preliminary design, others from the inability of the system to adapt to changing circumstances, politically tenacious decisions are often a contributing factor to the failure to craft laws that can stand the test of time. We argue that, as a result, some key aspects of international immigration policy are incoherent and mutually incompatible - new policies are often inconsistent with past policies and undermine their goals. Inconsistency makes policies less effective so powerful enthusiasm is needed to revise policies at a later date. Policies regarding impermanent visas, unaffiliated immigration, and humanitarian migrants offer examples of laxity and incompatibility. This article proposes key features of an integrated, coherent immigration policy from an economic perspective and how policymakers could better attempt to achieve policy consistency across laws and over time.
\end{abstract}

Keywords: anti-immigration, undocumented, factor, unauthorized, outcomes.

\section{Introduction}

International migration is a universal phenomenon and an unabated part of ever-expanding phenomenon of globalization. In this brief analysis, we will examine the condition of international migration in the world, placing the country in the regional context, in order to identify the scopes and challenges that international immigration demonstrates to the country and the migrants who cross its frontier. International migration is a global phenomenon and International migration is a multidimensional phenomenon and our full understanding needs a multidisciplinary direction drawing theoretical, methodological, and empirical insights from economics, sociology, demography, anthropology, geography, history, legal studies, political science, international relations, and most important security studies. There is a thematic expert report commissioned by the Global Commission on International Migration (GCIM), and the report is therefore evidence-based and focuses on irregular migration and actionable policy options. It relies on a variety of sources, including recent academic literature, policy statements published by a variety of governments, regional and international organizations, and various statements and articles in the public domain and also from earlier meetings of GCIM. The report emphasizes that irregular migration is a complex and diverse phenomenon [1][4].

Every country has the right to control their borders, and it would undermine the authenticity and credibility of GCIM to suggest otherwise. In certain parts of the world, policy on irregular migration is driven by the 
perception (whether accurate or not) that countries risk being 'overwhelmed' by large numbers of irregular migrants who embody threat to society and states. This report has seven main sections. First, the section dilemmas framing policy-making on irregular migration are outlined. Second, irregular migration is identified and apposite terminology and data sources considered. The next section supplies a brief overview of current global trends in relation to irregular immigration. The next section examines the ways and extent to which irregular migration constitutes a real or perceived threat to national security and human security. Fifth, the contribution of non-state actors to the development of policy in this arena is considered. The penultimate section examines policies and practices concerning the return of unauthorized migrants. Finally, alternative policy approaches are explored [4]. The impacts depend crucially on who comes, where they come from, the circumstances of their departure and arrival, what local communities they arrive in, what legal barriers and obligations they face. Sometimes, immigration can negatively affect employment for some groups during some periods, especially natives with similar skills, experience, and job preferences as migrants. However, it can also create more and better employment-by encouraging natives to upgrade professions, increasing labor force participation by natives, and filling labor shortages to ascent productivity. Similarly, immigration can either cost taxpayer's money or deliver fiscal benefits, or lead to either increased or decreased service quality. They depend on how policymakers choose to regulate labor markets, benefits systems, and mobility itself. Over the next few decades, migration streams will likely increase substantially and predictions give a hint by 2040 the number of working-age people will expand by 91 percent, or over 330 million in low-income nationals. Immigration can either contribute to or harm service quality [8]. Different policies will work in different settings, the policies demonstrated here should not be regarded as guides but as illustrations of the power that policymakers have to shape outcomes. Finally, it should be acknowledged that the current political climate around migration presents crucial challenges, some new policies are meant to stop migration, not shape it. The dispute on what works and what does not must come with sturdy engagement with policymakers and citizens on the potential benefits of addressing migration in pragmatic, realistic ways, along with the potential expenses and adjustments for certain groups. Our goal is not to draw blanket conclusions, but rather to draw attention to what policy choices have worked better than others in real world contexts [8]. In this study, however, our main intention is to pursue a new well-designed immigration policy relating to all sectors including human and state security for the benefit of the refugees as well as host communities, and can also determine the positive impacts of international migration in the world.

\section{Background of history:}

Few international agencies the International Organization for Migration (IOM) define "migrant" as someone who has lived in a state other than her/his country of regular residence or citizenship. This definition applies to both "legal" (regular) and "illegal" (undocumented or unscriptural) migrants. Some data of migrants are all estimates and instinctively vary from the real number of foreign nationals. Also, the legal status of migrants, particularly that of those who are outside of their nationals of citizenship or usual residence for extended periods of time, changes over time. For example, students may become workers, legal migrant workers may become illegal labor migrants by overstaying their visas, and undocumented migrants may become asylum-seekers or refugees. Moreover, someone who may qualify as a "refugee" or "migrant" in one nation may not be considered as such in another country because nationals apply different legal definitions and operational standards for non-nationals within their territory. Moreover, most of the human trafficking around the world goes undetected and therefore, statistics on victims of human trafficking are estimates and difficult to verify. Therefore, we need to use statistics on migrants, refugees, asylum seekers, and victims of human trafficking with caution and flexibility. The following table shows the refugees and asylum seekers by country/territory of asylum, mid-2018.

\begin{tabular}{|c|c|c|c|}
\hline $\begin{array}{c}\text { Country of asylum } \\
\text { or residence }\end{array}$ & Refugees & $\begin{array}{c}\text { Of whom assisted by } \\
\text { UNHCR }\end{array}$ & $\begin{array}{c}\text { Asylum-seekers } \\
\text { (pending cases) }\end{array}$ \\
\hline
\end{tabular}


Debolin Das et. al/ International Immigration Policy and Evaluating the impacts of Immigration

\begin{tabular}{|c|c|c|c|}
\hline China & 301,043 & 148 & 654 \\
\hline South Korea & 1,532 & 163 & 6,295 \\
\hline Japan & 2,462 & 372 & 16,324 \\
\hline Mongolia & 14 & 14 & 1 \\
\hline Russia & 314,507 & 7,071 & 2,088 \\
\hline
\end{tabular}

Table 1: Refugees and asylum seekers by country/territory of asylum, mid-2018 report of the United Nations High Commissioner for Refugees (UNHCR).

In this study, we are especially interested in human security, human development aspects of migration as well as new migration policy. "Human security" means to the individual security of persons, in contrast to "national security," and has three factors: freedom from scare, freedom from poverty, and freedom to live with human dignity. Each of these factors, or pillars, can and has been operationalized differently but in this study we will employ a widely accepted, if not impeccable, indicator for each of them as it assists us gauge the level of human security people revel, or the intensity of the threats they live under in terms of the three components of human security. Obviously, the level of human security (or insecurity) varies from person to person or from area to area within a state, the study of international migration has generally established that international migrants, including the several categories of boundary -crossing persons noted above, are particularly vulnerable to human security threats because they are away from home and live outside of the effective limits of their government's physical or legal protections and often find themselves beyond the protections of the governments of their host countries. In order to improve the positive developmental impact of international migration, advocates have impelled the international society to encourage developing countries to see integrate migration as an integral part of their national development strategy, and their recommendation has found its way into the 2030 Agenda for Sustainable Development adopted in 2015 by the United Nations Summit. The concept has been developed and elaborated to the point where countries can be compared according to how their people's human development stands relative other countries or how the same country changes its level of human development in the period of time. Human development index (HDI) is used for comparative purposes.

\begin{tabular}{|c|c|c|}
\hline Country & Year & $\begin{array}{c}\text { Most recent } \\
\text { value }\end{array}$ \\
\hline Japan & 2018 & 13.0 \\
\hline Korea, Rep & 2018 & 12.4 \\
\hline Czech Republic & 2018 & 5.7 \\
\hline Luxembourg & 2019 & 4.3 \\
\hline Belgium & 2019 & 5.6 \\
\hline Sri Lanka & 2017 & 4.2 \\
\hline Denmark & 2019 & 2.6 \\
\hline Costa Rica & 2019 & 1.1 \\
\hline Indonesia & 2017 & 1.0 \\
\hline India & 2017 & 0.7 \\
\hline Afghanistan & 2017 & 0.4 \\
\hline Niger & 2017 & 0.4 \\
\hline Mali & 2010 & 0.1 \\
\hline
\end{tabular}

Table 2: Number of hospital Bed per 1000 people, Data are from the World Health Organization. 
Debolin Das et. al/ International Immigration Policy and Evaluating the impacts of Immigration

\begin{tabular}{|c|c|c|}
\hline $\begin{array}{c}\text { Country or } \\
\text { dependency }\end{array}$ & $\begin{array}{c}\text { Physicians per } \\
\mathbf{1 0 , 0 0 0} \text { people }\end{array}$ & $\begin{array}{c}\text { 2007-2013 } \\
\text { Physicians } \\
\text { per } \\
\mathbf{1 0 , 0 0 0} \text { people }\end{array}$ \\
\hline Niue & 20 & 30 \\
\hline Tuvalu & 9 & 10.9 \\
\hline Nauru & 8 & 7.1 \\
\hline Saint Lucia & 1.1 & 1.1 \\
\hline Kiribati & 2 & 3.8 \\
\hline Cook Islands & 12 & 12 \\
\hline Marshall Islands & 5 & 4.4 \\
\hline Vanuatu & 1 & 1.2 \\
\hline Tonga & 3 & 5.6 \\
\hline Palau & 16 & 13.8 \\
\hline Saint Kitts and Nevis & 11 & 11 \\
\hline Samoa & 3 & 4.5 \\
\hline Liberia & 0.5 & 0.1 \\
\hline Bhutan & 0.5 & 2.6 \\
\hline Solomon Islands & 1 & 2.2 \\
\hline Micronesia & 6 & 1.8 \\
\hline Gambia & 0.5 & 1.1 \\
\hline Guinea-Bissau & 0.5 & 0.7 \\
\hline
\end{tabular}

Table 3: Number of physicians per 10,000 people of several country or dependency.

\section{International Immigration Policy}

\subsection{Present policy:}

Most countries in the world have different migration policies and among them, least number of international migration policy is comparatively migrant friendly and some are not refugee friendly. The world's population is growing significantly day by day. In developing countries, this population growth has a largely negative impact, especially on education, health, social security and quality of life. According to the report of World Bank in 2019, the world's population growth rate is $1.1 \%$ while life expectancy is rising. If a nation required a faster population growth than the natural growth would allow, it would need to increase immigration (in-migration) and limit emigration (out-migration). However, few countries net migration (immigration minus emigration) is near zero. The data for the latest year (2020) is available up until the midyear on the Table.

\begin{tabular}{|c|c|c|c|c|c|}
\hline Year & $\begin{array}{c}\text { Refugees under } \\
\text { UNHCR's mandate }\end{array}$ & $\begin{array}{c}\text { Asylum } \\
\text { Seekers }\end{array}$ & $\begin{array}{c}\text { IDPs of } \\
\text { concern to } \\
\text { UNHCR }\end{array}$ & $\begin{array}{c}\text { Stateless } \\
\text { persons }\end{array}$ & $\begin{array}{c}\text { Others of } \\
\text { concern }\end{array}$ \\
\hline 2015 & $16,110,280$ & $3,223,460$ & $37,494,172$ & $3,687,759$ & 870,688 \\
\hline 2016 & $17,184,291$ & $2,729,521$ & $36,627,127$ & $3,242,206$ & 803,084 \\
\hline 2017 & $19,940,568$ & $3,089,503$ & $39,118,516$ & $3,853,982$ & $1,596,125$ \\
\hline 2018 & $20,359,556$ & $3,501,627$ & $41,425,168$ & $3,851,981$ & $1,182,756$ \\
\hline 2019 & $20,414,675$ & $4,170,548$ & $43,503,362$ & $4,161,980$ & $6,140,622$ \\
\hline 2020 & $20,676,358$ & $4,176,545$ & $45,940,575$ & $4,158,375$ & $5,793,516$ \\
\hline
\end{tabular}

Table 4: IDMC data (2020) on internally displaced persons and the demographic data for the population. 
From the perspective of international migration, world's population has both positive and negative implications. On the positive side are limited emigration and immigration pressure, low administrative costs for handling emigration and immigration applications, little need to adjust its migration policy, low levels of illegal activities accompanying emigration and immigration (e.g., human, drug, and arms trafficking, and migrant smuggling), low law enforcement costs, low costs of social provisions to support foreign immigrants, and limited cultural frictions and misunderstandings. On the negative side, few countries receive very little of the benefits generally associated with international migration, e.g., employment, educational, and professional development opportunities. The Protocol against the Smuggling of Migrants by Land, Sea and Air, supplementing the United Nations Convention against Transnational Organized Crime was adopted by General Assembly resolution 55/25, and entered into force on January 28, 2004. Article 3 subparagraph (a) defines "smuggling of migrants" as "the procurement, in order to obtain, directly or indirectly, a financial or other material benefit, of the illegal entry of a person into a State Party of which the person is not a national or a permanent resident." Article 3 subparagraph (b) defines "illegal entry" as "crossing borders without complying with the necessary requirements for legal entry into the receiving State." The Protocol aims at preventing and combating the smuggling of migrants, as well as promoting cooperation among States parties, while protecting the rights of smuggled migrants and preventing the worst forms of their exploitation which often characterize the smuggling process. In this part we have studied about some countries immigration policy. We have also analyzed immigration from Mexico along USMexico border from 1978 to 2018.

\section{Family-sponsored Immigration}

180,000

160,000

140,000

120,000

100,000

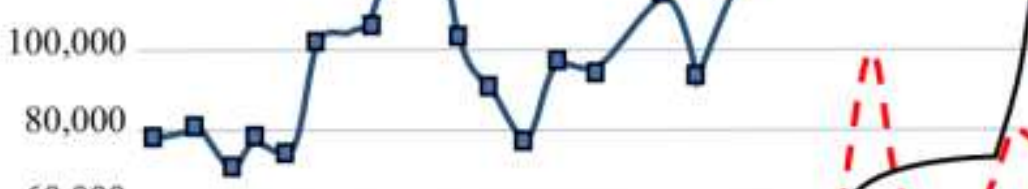

60,000

40,000

20,000

0

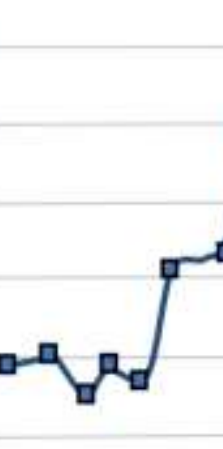

月
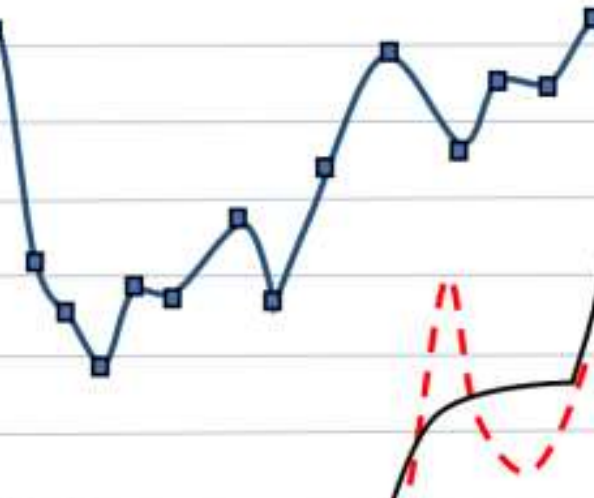

1

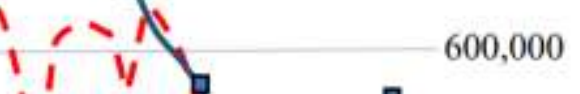

$1 \mathrm{~V} 600,000$

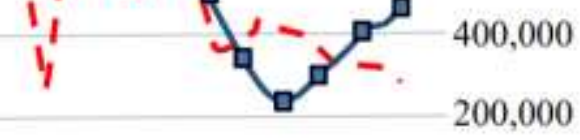

0

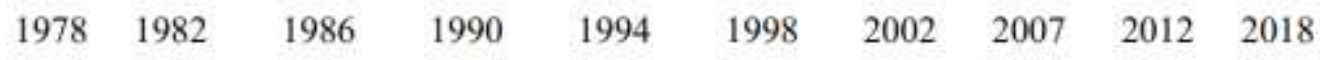 \\ — Immediate relatives $\quad---$ Other family members $\quad . \quad \cdots \cdots$ Apprehensions}

Figure 1: Family-sponsored Immigration from Mexico and Apprehensions along US-Mexico Border, 19782018.

The first is Australia, whose policy approach to irregular migration has proved uniquely effective, if heavily criticized. The extent to which lessons might be learned by other destination states is considered. The second is South Africa, which is included as an example of a Developing World destination for irregular migrants where a policy framework is evolving. The final case study is China, which is a country of origin for a 
significant number of irregular migrants, and is developing policies to try to reduce outflows. There are a series of reasons why such policies have failed to achieve their goals. First, and as alluded to in the paper, some of the factors shaping migration are largely beyond the control of direct state intervention, such as globalization, conflict and widening economic disparities between different parts of the world. A second reason is that once a migration becomes established, its momentum can be very hard to stop. A third reason is that control policies often have unintended consequences. Although the nature of the linkage is more complex that many people assume, most commentators agree, for example, that one consequence of control policies has probably been to fuel the growth in migrant smuggling. In this respect, there have been particular concerns about the impacts of control policies on asylum seekers. It is increasingly the case that asylum policies are being developed in few countries as a subset of migration policies, rather than part of a refugee policy. As a result, many asylum policies are becoming control-oriented and losing the protection focus of refugee policies (UNHCR 2004a). Some country and their policies:

Australia: Australia stands out as a country which has effectively reduced arrivals of irregular migrants (although there is still a problem of regular migrants who overstay). Following points summarizes the policy initiatives that have been combined to such effect.

- legislation - targeting slavery, sexual servitude and deceptive recruiting; organized migrant smuggling; domestic violence against spouses; and organized crime

- combating illegal work - law enforcement

- including intelligence gathering, training, international liaison, coastal surveillance

- international cooperation

- through full participation in regional processes and by signing relevant international instruments

- economic assistance for countries or regions that are the source of illegal migrants

- including education, targeted economic development and projects for the victims of trafficking

- research and data collection

- services for the victims of trafficking and education.

South Africa: South Africa is included as an example of a Developing World destination country where a policy framework is being developed. Its main characteristics are summarized as follows.

- $\quad$ strengthened physical barriers

- a computerized travelers' database operating at all ports of entry that verifies the authenticity of visas - introduction of 'carrier sanctions'

- a pool of fingerprints of citizens, permanent residents, asylum seekers and deportees that have facilitated the detection of multiple identities, fraudulently obtained documentation and unauthorized entry

- greater emphasis on inspection of premises and service provides known to accommodate undocumented migrants, along with increased rate of prosecution of employers of undocumented migrants

- $\quad$ proactive engagement with neighboring states, regional approach, bi-lateral meetings with neighboring states. [4] 
Debolin Das et. al/ International Immigration Policy and Evaluating the impacts of Immigration

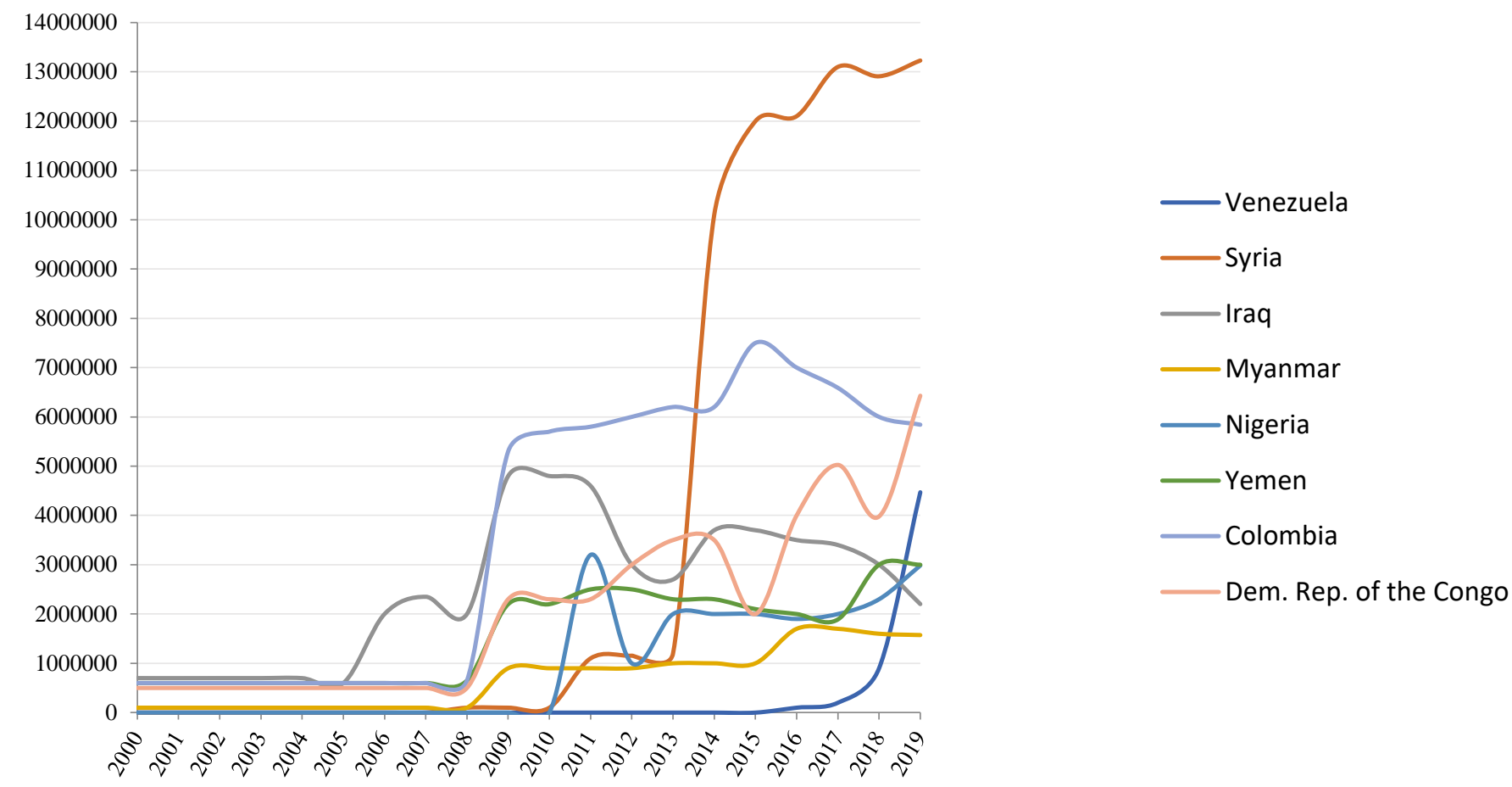

Figure 2: Forcibly Displaced People by Country of Origin 2000 to 2019; source-UNHCR refugee population

\subsection{Proposed policy:}

Undocumented Immigrants is a term used to describe foreign nationals who enter a country for purposes of permanent resettlement. The term undocumented immigrant has been operationalized using certain factors:

- legally entered the nation state or territory but remained in the country after their visa/permit expired;

- received a negative decision on their refugee application but remained in the country;

- experienced changes in their socioeconomic position and could not renew residence permit but remained in the country;

- used fraudulent documentation to enter the country or territory; or

- unlawfully entered the country or territory, including those who were smuggled.

The immigration laws in most countries, including in the USA and Canada, do not categorize "temporary workers" as immigrants, when temporary workers decide to settle permanently in their new nations, they are then categorized as immigrants. In general, there are three broad categories of immigrants: (1) voluntary migrants who come to join relatives already settled in the receiving nation or to fill particular jobs for which expertise may be lacking among nationals; (2) refugees and asylum seekers who enter the state to avoid persecution; and (3) undocumented immigrants who enter the state illegally.

\begin{tabular}{|c|c|c|c|c|c|}
\hline $\begin{array}{l}60 \% \text { originate } \\
\text { from just five }\end{array}$ & Country & Million & $\begin{array}{l}39 \% \text { hosted in } \\
\text { five countries. }\end{array}$ & Country & Million \\
\hline countries. & $\begin{array}{l}\text { Syrian Arab } \\
\text { Republic }\end{array}$ & 6.6 & & Turkey & 3.6 \\
\hline $\begin{array}{l}\text { More than two } \\
\text { thirds of all } \\
\text { refugees under }\end{array}$ & Venezuela & 3.7 & $\begin{array}{l}\text { Turkey hosts the } \\
\text { largest number }\end{array}$ & Colombia & 1.8 \\
\hline $\begin{array}{l}\text { UNHCR's } \\
\text { mandate and }\end{array}$ & Afghanistan & 2.7 & $\begin{array}{l}\text { of refugees, } \\
\text { with } 3.6 \text { million }\end{array}$ & Pakistan & 1.4 \\
\hline $\begin{array}{l}\text { Venezuelans } \\
\text { displaced abroad }\end{array}$ & South Sudan & 2.3 & $\begin{array}{l}\text { people. } \\
\text { Colombia is }\end{array}$ & Uganda & 1.4 \\
\hline
\end{tabular}


Debolin Das et. al/ International Immigration Policy and Evaluating the impacts of Immigration

come from just

five countries.

(as of mid-

Myanmar

1.0 second with 1.8

million (as of

mid-2020).
Germany

1.1

Table 5: Highest number of refugees displaced from and hosted in five countries.

People not only migrate because of poverty, lack of services, lack of safety, high crime, crop failure, drought, flooding, war but also in the hope of a better life, better services, higher employment, more fertile land, good climate, safer, political stability, more wealth, less crime, lower risk from natural hazards.
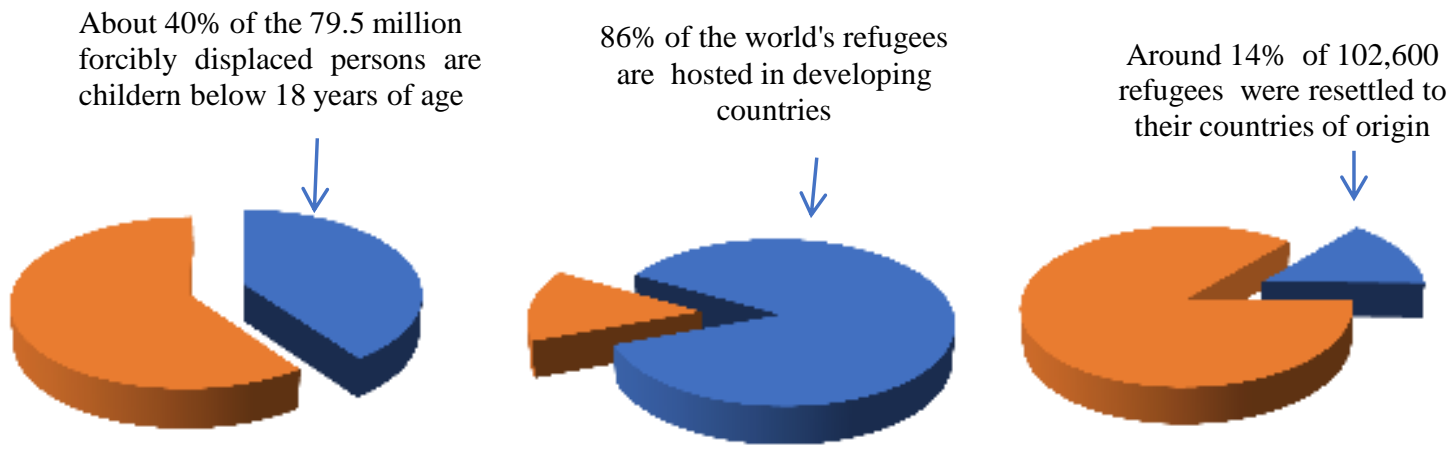

Figure 3: Graphical representation by percentages; data source-UNHCR.

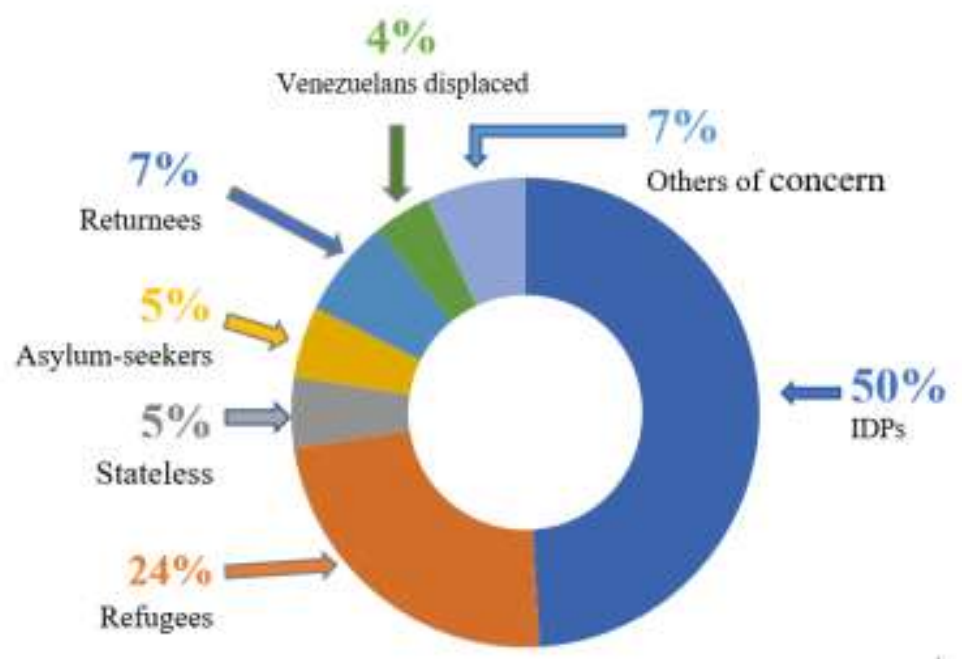

Figure 4: People of concern to UNHCR worldwide.

Immigration policies are generated by various sects or stakeholders including think tanks, branches, bureaucrats, politicians, congressional staff, and academics. Immigration policies are usually drafted by considering the level of technical and implementation feasibility as well as their acceptable value [5]. We found that in many countries most of these anti-illegal immigration initiatives were proposed under a "policy" or "political" umbrella to attract voters in certain localities with strong "anti-immigration" sentiments. In addition, using the multiple streams (MS) model led us to further understand how the sources 
of immigration enforcement power vary by country and jurisdiction. Countries use the judiciary, legislative, or executive departments to introduce these powers. Powers come through a complex body of statutes, rules, and case law governing entry into a particular country. However, there is a general consensus that immigration control is an exercise of the executive power; that is, it is exercised by the executive arm of the government. A unique characteristic encountered in the field of immigration law is the retention of discretion, which is less amenable to control than the application of specific rules and standards.

Emigrants can also benefit their own nationals by exchanging knowledge and technologies that diversify and benefit the economy, and the prospect of emigration can lead to greater investment in human capital. And, regardless of whether the host state is developed or developing, the potential benefits of hosting refugees include higher incomes and employment rates for natives. In this paper, we suggest the following idea (seven topics) to consider that policies shape the effects of migration by exploring case studies.

1. If immigrants fill labor gaps, immigration creates jobs and raises incomes. Policies that allow immigrants to fill labor shortages create jobs, increase labor force participation rates, and increase incomes for natives. When policies restrict immigrants from filling shortages, economic opportunities are lost.

2. Well-designed temporary migration programs fill critical labor needs, while also minimizing the risk of overstays. Temporary migration programs are an effective means to fill labor shortages. Whether they are accompanied by visa overstays and violations of workers' rights depends on the incentives created by the program.

3. Creating legal pathways for migration can reduce irregular migration. When policymakers create new legal channels for migration, irregular migration can decrease - when other key elements are in place. When these legal channels disappear, irregular migration may reappear.

4. The fiscal impact of new immigrants is a policy choice, with potential contributions that go far beyond individual-level taxes paid. Immigrants can (and often do) contribute more in taxes than they receive in government services over time-especially if policies support and enable their successful integration into labor markets.

5. Immigrants contribute to the economy as entrepreneurs, investors, and innovators - if they are allowed to. When policies lower barriers to business ownership, immigrants invest in their host economy, hire natives, and boost economic growth.

6. Policy decisions in migrant origin and destination countries turn skilled migration into a drain or a gain. Skilled emigration creates a range of potential economic benefits for the migrants, the destination country, and the origin country-benefits that can be turned into real harms by policies designed for an immobile world. Skill partnerships between origins and destinations offer one path toward mutual benefit.

7. With well-designed policies, immigrants can have a positive impact on the quality of service delivery. Immigration can either contribute to or harm service quality. Policy choices, such as creating integrated health systems for refugees and host communities, can determine the impact.

Therefore, while our case studies sometimes focus on host country income level, many of the policy lessons can be extended across migrants and refugees and income levels, with the warning that the degree of potential benefit and expense is contingent on the context. We do not suggest that the policies we present as positive perspective are perfect; each has aspects that policymakers should seek to emulate, but they also have shortcomings. For this reason, we take care to elaborate on how the policies could be improved. Moreover, through migration policies alone human mobility cannot be controlled completely. We also do not recommend that the positive examples can be applied in all contexts. 
This includes a recognition that refugees or migrants will continue to move, likely in increasing numbers, and whether a person moves on regular or irregular terms in and of itself has serious policy and practical implications. Immigration policymakers who aim to create a cohesive, coherent system should keep several key factors in mind. They should consider the interconnected nature of many migrant streams. Policymakers should consider the effects of an immigration policy on upcoming time and future flows. Policymakers aiming to stem unauthorized immigration should recognize that tougher border enforcement can help keep unauthorized immigration in check but is costly and has far-reaching unintended consequences. At this point creating more legal channels for less-educated immigrants to enter the country would also help reduce unauthorized immigration. Policymakers also need to decide how to best deal with unauthorized immigrants already present in the country. Policymakers need to build more flexibility into the immigration system. Rigid caps for permanent residents and some categories of temporary foreign workers have resulted in tremendous backlogs and inefficient lotteries and have discouraged countless potential would-be immigrants from applying or staying in the host states; they may even motivate few companies to open operations overseas in lieu of domestically. Finally, policymakers should try to make commitments that remove the possibility of temporally inconsistent policies or that widen the gap between policy and practice.

Immigration can be denoted by the following mathematical equation:

$$
\begin{aligned}
\text { immigration } \propto & \left\{\frac{(\text { labor gap } \times \text { cheap labor cost })+(\text { education } \times \text { skill } \times \text { health })}{\text { least developed countries }+ \text { minimal HDI value }+ \text { Political instability }}\right\} \\
& + \text { emotion of humanity }
\end{aligned}
$$

$\operatorname{im} \propto\left\{\frac{(L g \times L c)+(e \times s \times h)}{L d c++M h v+P u s}\right\}+h e$

where,

$$
\begin{aligned}
& \text { im = immigration in host country } \\
& \mathrm{L}_{\mathrm{g}}=\text { labor gap; eg: } 1,2, \ldots 100, \ldots 500 \ldots \ldots \\
& \mathrm{L}_{\mathrm{c}}=\text { cheap labor cost; eg: } \$ 5, \$ 10, \ldots \ldots \ldots \\
& \mathrm{L}_{\mathrm{dc}}=\text { least developed countries where they from } \\
& \mathrm{M}_{\mathrm{hv}}=\text { minimal HDI value; like } 0.39,0.41,0.55, \ldots \ldots \\
& \mathrm{P}_{\mathrm{us}}=\text { Political unstable state } \\
& \mathrm{h}_{\mathrm{e}}=\text { emotion of humanity } \\
& \mathrm{e}=\text { education level; standard } 4, \text { standard } 5, \ldots \text { secondary, higher secondary, } \ldots \\
& \mathrm{s}=\text { skill; industry, farming, } \ldots . . \text { etc } \\
& \mathrm{h}=\text { health fitness; infection disease free. }
\end{aligned}
$$

With regard to employment-based migrants, a consistent policy would readily grant permanent resident visas to temporary foreign workers who meet the qualifications for permanent visas when their temporary visas expire and then no need to meet them a higher standard and just wait for a certain time for a visa to become available. And removing the ability of a new administration to easily reverse course and renege on commitments to admit certain refugees or other immigrants seems like a must for temporally consistent policy [9].

\section{Security threats and Concepts on a practical view (Impacts and results):}


In recent years, international migration has made its way to the forefront of the security agendas of several states, particularly in Europe, North America, and even in Asia [6]. The perception of immigration as a threat to security has developed alongside the rapid increase in the number of immigrants worldwide. Due to the expansion of the concept of security, a multitude of issues such as those relating to the environment, poverty, and international migration have been labeled as security risks or threats.

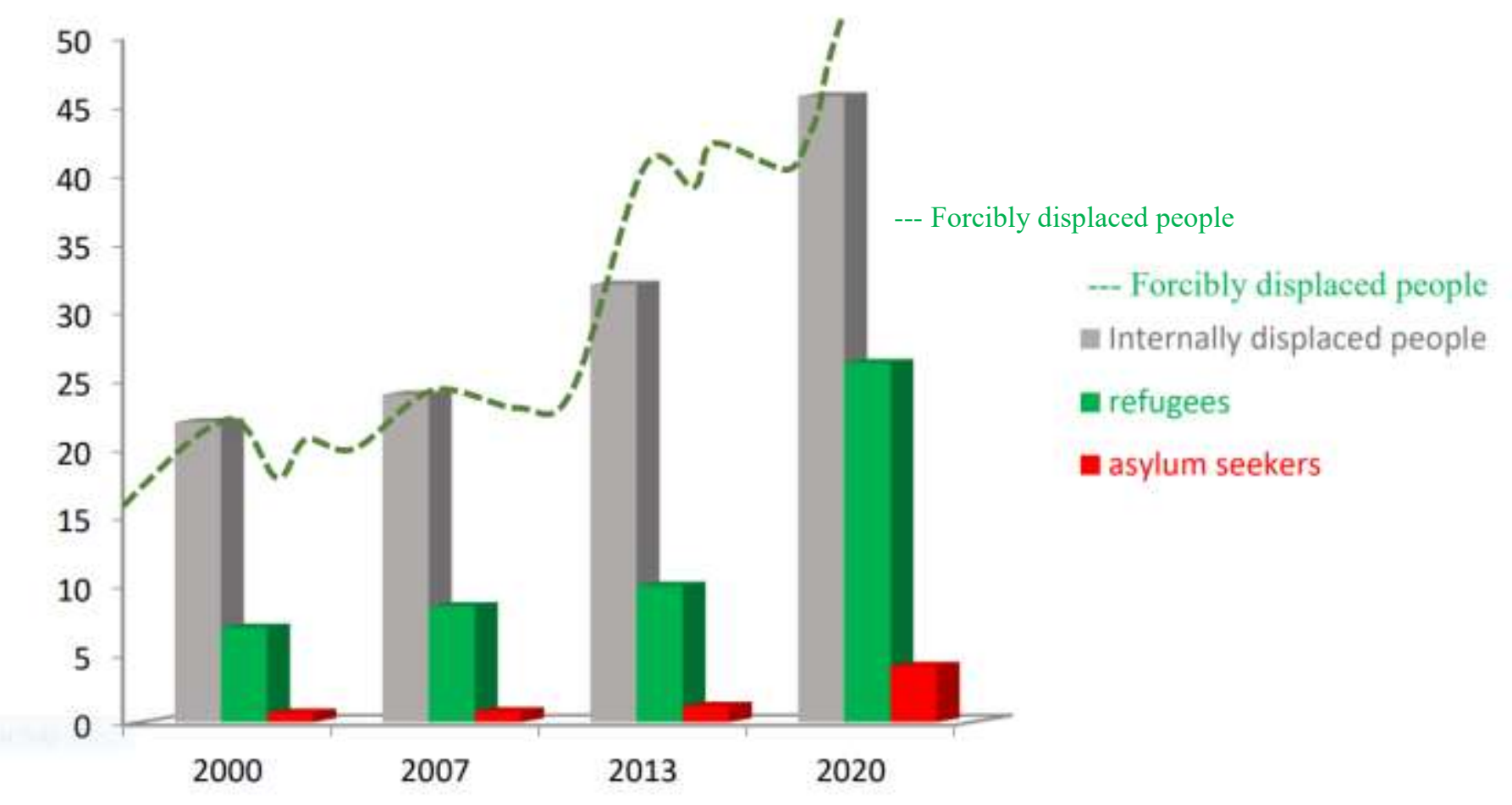

Figure 5: Forcibly displaced people worldwide in different years.

According to the International Organization for Migration, immigration from one country to another present various challenges, including "unsafe migration, fraud, border inspection avoidance, visa violations and an increased incidence of human trafficking."16 An IOM report notes, "Due to the remoteness of the country's vast international borders and challenges faced by its border and identity management systems, fraud, border inspection avoidance and visa violations are significant challenges for the Government of hosting countries and contribute to similar problems in neighboring countries." That is, the government is apparently concerned about some of the human security and human development aspects of international migration. 
Global forced displacement

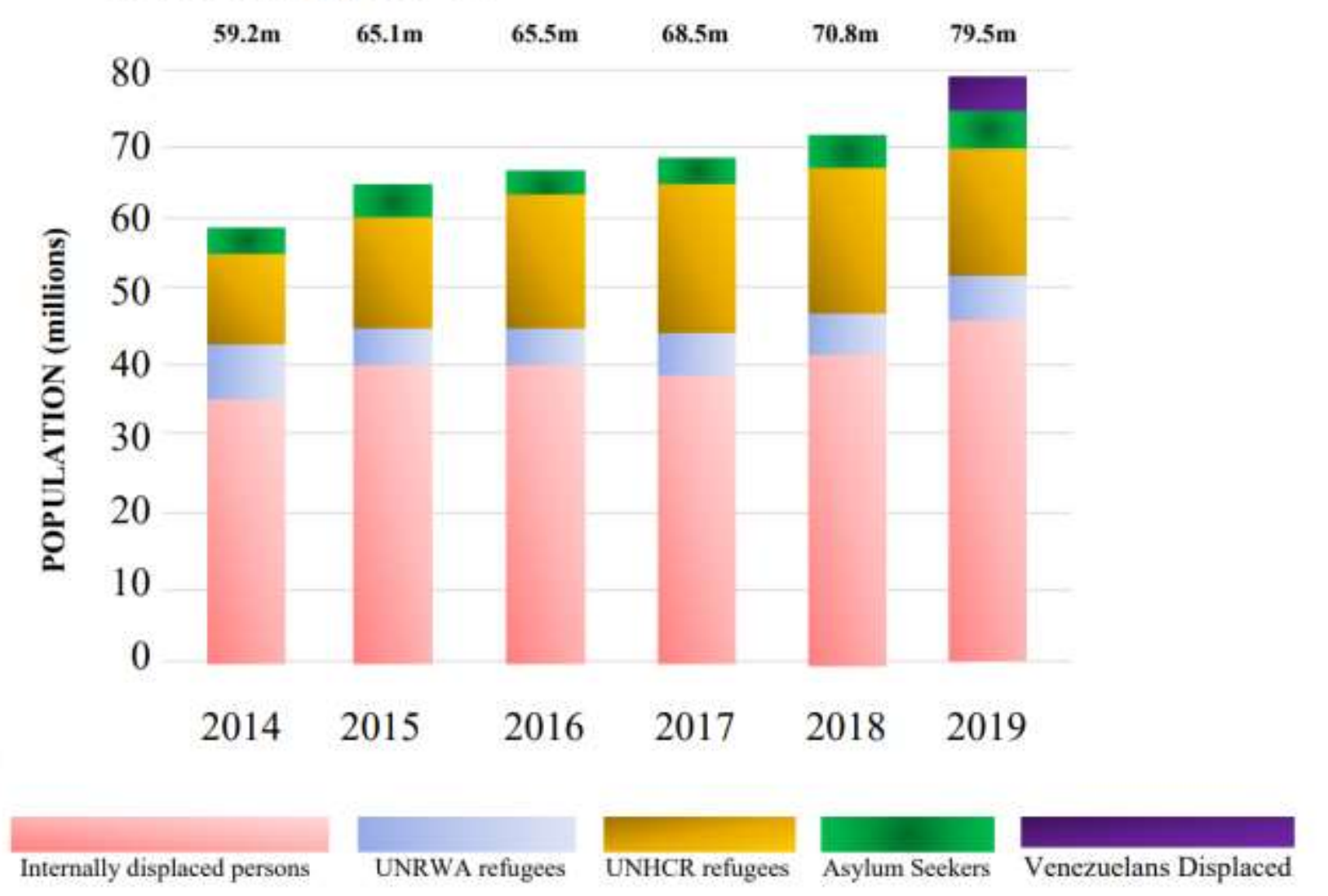

Figure 6: Globally forced displacement population(millions) from 2014 to 2019.

The rights of migrant workers, asylum-seekers and refugees, victims of human trafficking, and smuggled migrants are enshrined in various international conventions. Relevant conventions and their supplementary protocols include: 1951 International Convention relating to the Status of Refugees (Refugee Convention); 1967 Protocol relating to the Status of Refugees; International Convention on the Protection of the Rights of All Migrant Workers and Members of Their Families (Migrant Workers Convention); UN Convention against Transnational Organized Crime; Protocol to Prevent, Suppress and Punish Trafficking in Persons, Especially Women and Children, supplementing the United Nations Convention against Transnational Organized Crime (Human Trafficking Protocol); Protocol against the Smuggling of Migrants by Land, Sea and Air, supplementing the United Nations Convention against Transnational Organized Crime (Migrant Smuggling Protocol); ILO Convention concerning Migrations in Abusive Conditions (C097); and the Promotion of Equality of Opportunity and Treatment of Migrant Workers (C143). Table 4 shows the status of ratifications by the Northeast Asian countries of these treaties [3] [10].

\begin{tabular}{|c|c|c|c|c|}
\hline $\begin{array}{c}\text { Convention } \\
\text { Country }\end{array}$ & CMW & RC & RP & CTOC \\
\hline China & No Action & Acceded & Acceded & Ratified \\
\hline Japan & No Action & Acceded & Acceded & Signatory \\
\hline North Korea & No Action & No Action & No Action & Acceded \\
\hline South Korea & No Action & Acceded & Acceded & Ratified \\
\hline Mongolia & No Action & No Action & No Action & Acceded \\
\hline Russia & No Action & Acceded & Acceded & Ratified \\
\hline
\end{tabular}

\begin{tabular}{|l|c|c|c|c|} 
Convention & TIPP & MSP & ILO C097 & ILO C143 \\
\hline
\end{tabular}


Debolin Das et. al/ International Immigration Policy and Evaluating the impacts of Immigration

\begin{tabular}{|c|c|c|c|c|}
\hline Country & & & & \\
\hline China & No Action & No Action & No Action & No Action \\
\hline Japan & Signatory & Signatory & No Action & No Action \\
\hline North Korea & No Action & No Action & No Action & No Action \\
\hline South Korea & Ratified & Ratified & No Action & No Action \\
\hline Mongolia & Acceded & Acceded & No Action & No Action \\
\hline Russia & Ratified & Ratified & No Action & No Action \\
\hline
\end{tabular}

Table 6: Status of ratifications by few northeast Asian countries of principle international conventions concerning migrants, refugees, and human trafficking and migrant smuggling.

CMW: International Convention on the Protection of the Rights of All Migrant Workers and Members of Their Families

RC: 1951 Refugee Convention

RP: 1967 Protocol relating to the Status of Refugees

CTOC: UN Convention against Transnational Organized Crime

TIPP: Protocol to Prevent, Suppress and Punish Trafficking in Persons,

Especially Women and Children, supplementing the United Nations Convention against Transnational Organized Crime MSP: Protocol against the Smuggling of Migrants by Land, Sea and Air, supplementing the United Nations Convention against Transnational Organized Crime ILO C097: ILO Convention concerning Migration for Employment (Revised 1949) ILO C143: ILO Convention concerning Migrations in Abusive Conditions and the Promotion of Equality of Opportunity and Treatment of Migrant Workers "Acceded": The state has expressed its consent by acceding to the treaty and where the treaty has entered into force. "Ratified": The state has expressed its consent by ratifying the treaty and where the treaty has entered into force. "Signatory": The state provided a preliminary endorsement of the instrument and its intent to examine the treaty domestically and consider ratifying the instrument. "No action": The state did not express its consent [2].

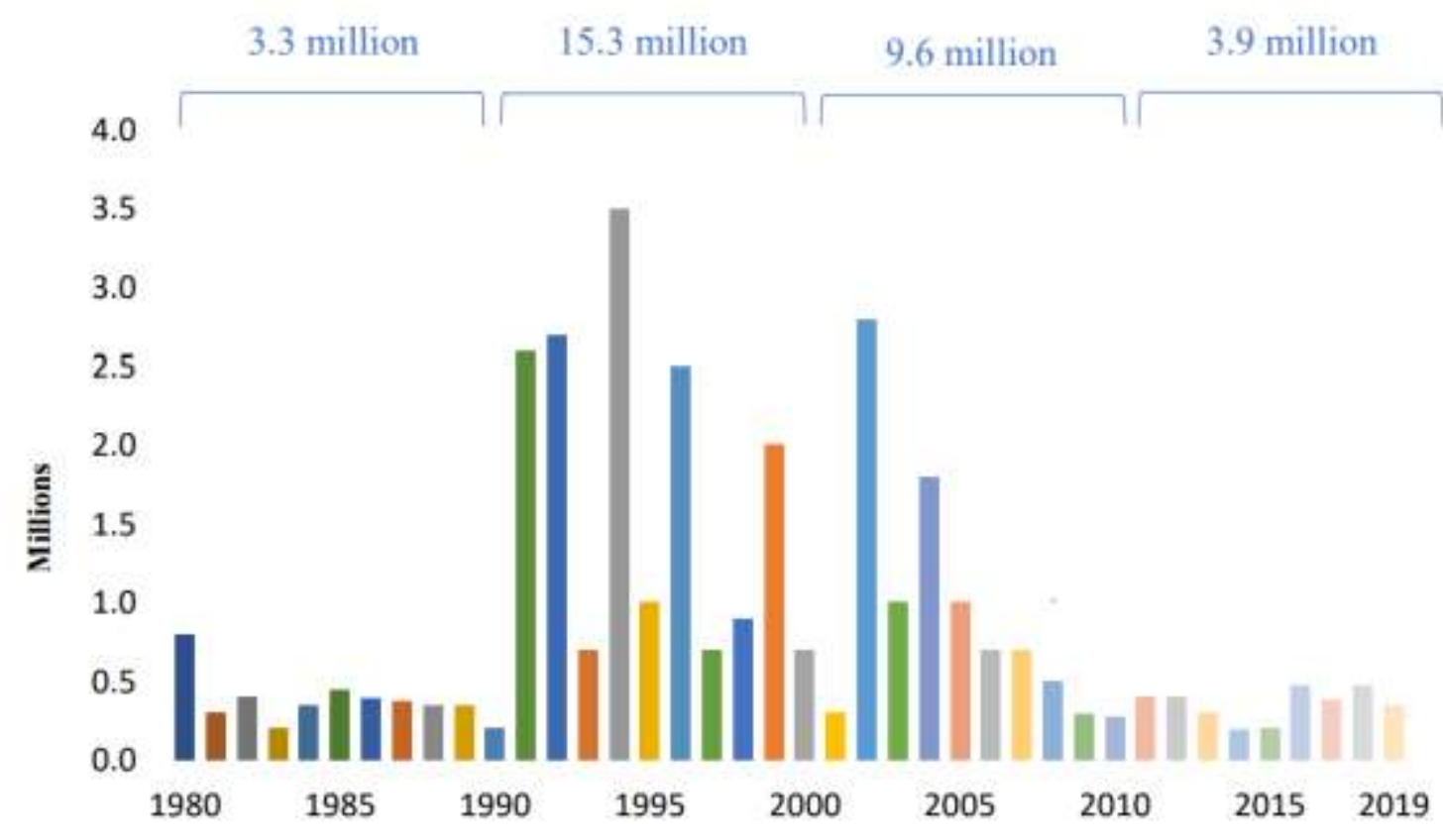

Figure 7: Refugee returns by decade from 1980 to 2019. 
The International Convention on the Protection of the Rights of All Migrant Workers and Members of Their Families was adopted by the UN general assembly in December 1990. It is by far the most comprehensive international legal instrument promoting the rights of migrants. It enables all those persons who qualify as migrant workers under its provisions, to enjoy their human rights regardless of their legal status. Number of security factors are concerned which are presented in this paper.

State Security: In political and media discourses, irregular migration is often described as constituting a threat to state sovereignty. Put simply, the argument is that states have a sovereign right to control who crosses their borders, and that by undermining that control irregular migrants therefore threaten sovereignty. It follows that stopping irregular migration is fundamental to reasserting full sovereignty. In certain, more extreme discourses, irregular migration has also been perceived as a threat to state security. Specifically, irregular migration and asylum, it has been suggested, may provide channels for potential terrorists to enter other countries. Given the sensitivity of the current debate, extremely careful analysis is required before supporting such potentially incendiary conclusions. The argument developed is that while irregular migration may in certain circumstances threaten state sovereignty or security.

Human security: Another aspect that is often lost in current debates about irregular migration is that it also has adverse consequences for migrants themselves. This is most obviously the case for the victims of trafficking, who are usually women or children, and are often exploited in domestic work or the sex industry. Such can be the level of abuse of their human rights, that some commentators have compared contemporary human trafficking with the slave trade. One criticism of the UN Protocols on smuggling and trafficking is that they emphasize the human rights abuses associated with trafficking but underplay those that can arise as a result of migrant smuggling. Research on the smuggling of asylum seekers in particular has demonstrated that smuggling can also expose migrants to sources of economic, social and political vulnerability. It is not just the process of moving in an irregular fashion that can jeopardize migrants, but also their irregular status. Irregular migrants often work in precarious and dangerous jobs; they are excluded from health, education and other social welfare provisions, and they can be subject to exploitation in the housing market. Their status often makes them unwilling to engage with authorities, and this is a particular concern where they may have a valid asylum claim. The supposed danger of immigration to the societal security of a state is not an objective and universal threat, but rather a subjective threat, dependent on the ways in which the receiving state defines itself. For instance, while some states may view multiculturalism as undesirable, other states may pride themselves on their cultural diversity [11].

Economic Security: Another way in which immigration has been argued to pose a threat to a state's national interest is through its impact on the state's economy. Immigration has, and will continue to have, a significant economic impact on both the receiving country and the country of origin. Migration in general can threaten economic stability by increasing employment competition; undermine social stability where it is combined with the rise of xenophobia and lack of integration. While immigration has economic advantages and disadvantages, the expansion of the definition of security to encompass the economic sector has brought increased attention to the economic challenges caused by immigration, and immigration has, as a result, been labeled as a security issue. It is economic migrants as well as refugees and asylum seekers that are perceived to threaten the economic security of a state [12]. Labor migration can be argued to pose a threat to the economic security of both the sending and the receiving state. According to this argument, the emigration of highly skilled and qualified workers from developing countries in the global South to developed states in the global North results in a "brain drain" in the sending country, as well as undesirable economic consequences in the receiving country. 
Is it possible, migrants can, for example, be associated with criminal activities - on the part of migrant smugglers and human traffickers, and also migrants themselves who engage in 'survival crimes'. In addition to societal and economic security, internal security has also emerged as an aspect of security which is threatened by immigration. Migration can be associated with multiple challenges associated with increasing religious, cultural and ethnic heterogeneity. But these challenges arise as much from regular as they do irregular migration, as detailed in another GCIM expert report. The notion of immigration as a threat to internal security has been present since the 1980s. As highlighted by Huysmans, the Schengen Agreement and Convention of Dublin connected immigration to terrorism, international crime, and border control.

Misperceptions: That irregular migrants threaten either state sovereignty or security is often a misperception. It needs to be corrected through careful and objective analysis and presentation of the available evidence, and concerted dialogue between governments, the media and citizenry. The following arguments need to be made more strongly. First, numbers matter. Wrapped up in the argument that irregular migration threatens state sovereignty is the perception that states are, or risk, being 'flooded' or overwhelmed by enormous numbers of irregular migrants. In reality, as discussed in the preceding section, the political significance of irregular migration generally outweighs its numerical significance. Irregular migration does occur in significant numbers, but in most countries it represents a fairly small proportion of total migration. Second, irregular migrants are often imputed with tainted intentions without any substantiation. Two particularly frequent assumptions are that irregular migrants participate in illegal activities and that they are associated with the spread of infectious diseases, and especially HIV/AIDS. Both these assumptions are gross generalizations. Some irregular migrants (and asylum seekers) are criminals and some carry infectious diseases: but most do not. Misrepresenting the evidence criminalizes and demonizes all irregular migrants. It can encourage them to remain underground, and in the case of asylum seekers not to lodge applications. It also diverts attention from those irregular migrants who actually are criminals and should be prosecuted, and those who are diseased and should be treated. To easily understand the actual situation, we've tried to demonstrate the average wait time in months of third preference employment-based immigration of few countries or territory.

\begin{tabular}{|c|c|c|c|c|}
\hline Time Period & China & India & Philippines & Rest of World \\
\hline $1992-1996$ & 9 & 4 & 26 & 0 \\
\hline $1997-2001$ & 24 & 28 & 1 & 0 \\
\hline $2002-2007$ & 17 & 21 & 16 & 12 \\
\hline $2008-2012$ & 75 & 90 & 62 & 63 \\
\hline $2013-2019$ & 82 & 129 & 78 & 39 \\
\hline
\end{tabular}

Table 7: Average Wait Time in Months of Third Preference Employment-based Immigrants.

Migration has both positive and negative impacts on both the origin location and migrants themselves.

Positive impacts on the origin location

- Unemployment can reduce

- Less pressure on natural resources

- Migrants bring new skills and knowledge

- There is less pressure on services; like education, healthcare

- Remittances- boosting the local economy

Negative impacts on the origin location

- There are fewer people to pay tax

- Brain drain could have a negative impact on economic development 
- Families separated by borders

- There are often gender imbalances

Positive impacts of migration on migrants

- The opportunity to get a better job

- Improved quality of life

- Safety from conflict

- The opportunity for a better education

Negative impacts of migration on migrants

- Migrants may run out of money

- Issues communicating due to language barriers

- Securing accommodation or housing

- Illness lack of healthcare

- Migrants can be exploited

- Migrants may experience racism

Irregular migration also impacts on the ability of governments to expand regular migration channels. The importance for a government to be perceived by citizens to be in control cannot be underestimated. If irregular migration exists, it is not unreasonable for voters to ask why even more migration is required. And if governments cannot control irregular migration, why should anyone believe they can regulate any other form of migration.

A Decade of Displacement (2010 - 2019)

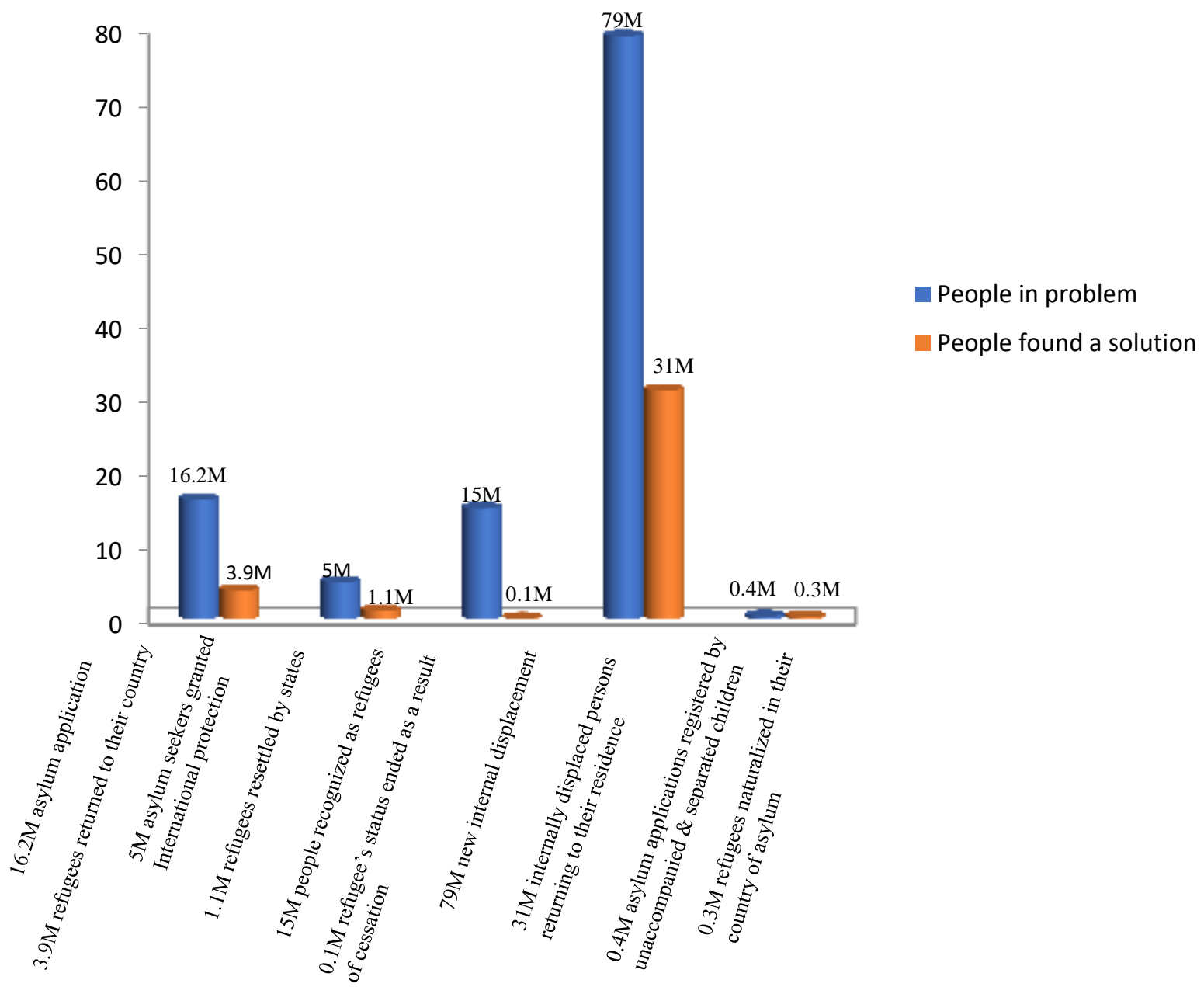


Figure 8: A Decade of Displacement (2010 - 2019)

Labor market demands: There is no doubt that most receiving states, especially in the industrialized world, do have the political will to act, for certain reasons. It is estimated, for example, that in 2002 alone Canada, Germany, the Netherlands, the United Kingdom (UK) and the United States (USA) together spent about US\$17 billion in trying to respond to the problem of irregular migration (Martin 2003) [9]. What is undeniable; nevertheless, is that from an economic perspective irregular migration is actually quite functional for many destination states. As a result of deregulation, liberalization and flexibilization, there is demand for various forms of unskilled and semi-skilled labor employed under precarious conditions. Irregular migrants provide a cheap source of labor and are often willing to work in sectors in which regular migrants and nationals are not. Unless its economic rationale is properly understood, efforts to manage irregular migration are unlikely to succeed. Using the multiple streams (MS) model of policy process, we were able to deconstruct the framework that explains how immigration policies are made and implemented.

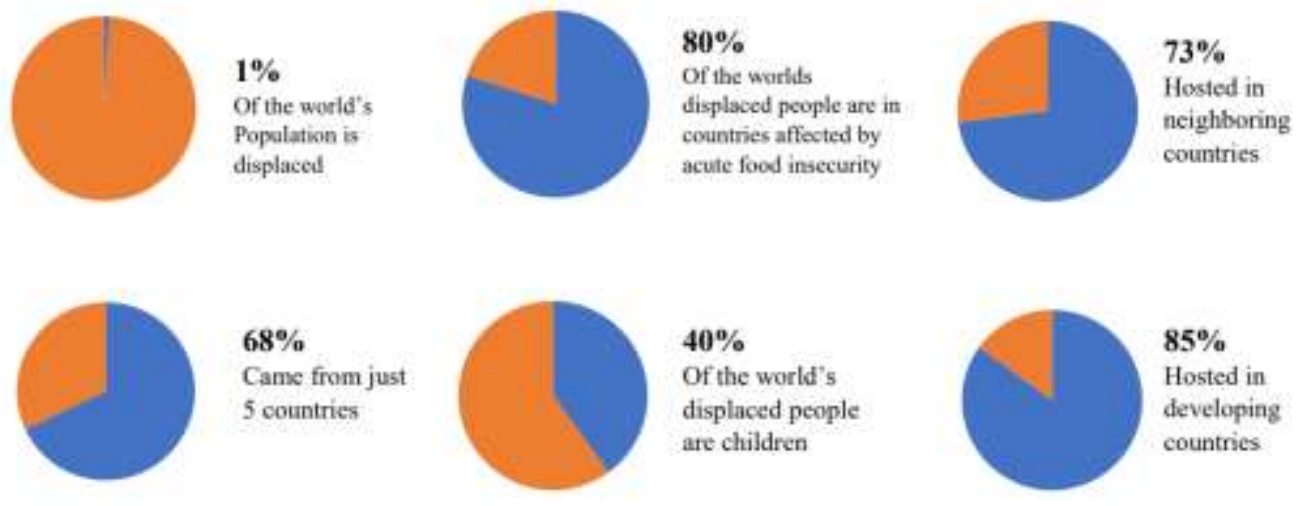

Figure 9: Status of refugees in different stages through pie chart.

5. Conclusion: A different approach is required worldwide to respond to the issue of undocumented illegal migration and unauthorized cross-border flows. There is no doubt that host country's citizens will expand their search for economic, social, and cultural opportunities farther and wider throughout the world. However, developed and developing countries will remain the most important destinations for most refugees and migrants because of geographic proximity, economic ties, and cultural affinity. Due to country's economy, geographical position, and restrictive immigration policy, most of country will likely remain a destination for only a limited number of international or labor migrants, refugees, human trafficking, and migrant smuggling. One of the most common concerns about immigration is that it diminishes wages as well as employment rates among natives. The vast majority of research finds that the average labor market effect of immigration and refugee inflows to both developed and developing countries is small or null [8]. Finally, the human security and development challenges citizens face, both inside and outside of their country, are universal challenges. If the neighboring countries can effectively deal with their problems, their emigration pressure will be reduced, thus diminishing immigration or transit pressure on host country. Although this paper discusses policy constructions on immigrants on few key factors, this study has implications for how immigrants and public assistance are constructed in policy circles in times of cutbacks. On the other hand, policy constructions that show support for immigrants and public assistance resonate with values around compassion and the inclusion of immigrants as active and contributing members to a new society [7].

\section{References:}


1. Aida Sole I Auro, The impact of immigration on health longevity and dependency of the elderly in the Spanish and European population, Ph.D. dissertation, University de Barcelona, July 2009.

2. Tsuneo Akaha, International Migration and Human Security and Development in Mongolia, The Mongolian Journal of International Affairs, Middlebury Institute of International Studies at Monterey, USA. DOI: https://10.5564/mjia.v20i0.1024

3. Robert W Aldridge, Laura B Nellums, S Bartlett, AL Barr, Parth Patel, R Burns, S Hargreaves, JJ Miranda, S Tollman, JS Friedland, I Abubakar, Global patterns of mortality in international migrants: a systematic review and meta-analysis, Centre for Public Health Data Science, Institute of Health Informatics and Institute for Global Health, Page: 2517, 5 December 2018.

4. Khalid Koser, Irregular migration, state security and human security, A paper prepared for the Policy Analysis and Research Programme of the Global Commission on International Migration, University College London, September 2005.

5. O Martinez, E Wu, T Sandfort, B Dodge, AC Dieguez, R Pinto, AD Rhodes, E Moya, SC Baray, Evaluating the Impact of Immigration Policies on Health Status Among Undocumented Immigrants: A Systematic Review, J Immigr Minor Health. Author manuscript; available in PMC 2016 June 01.

6. Neil K. Mehta, Irma T. Elo, Michal Engelman, Diane S. Lauderdale, and Bert M. Kestenbaum, Life Expectancy Among U.S.-born and Foreign-born Older Adults in the United States: Estimates From Linked Social Security and Medicare Data, Demography. 2016 August; 53(4): 1109-1134. doi:10.1007/s13524-016-0488-4.

7. Grace J. Yoo, Immigrants and Welfare: Policy Constructions of Deservingness, Journal of Immigrant \& Refugee Studies, Vol. 6(4), 2008, pp 490-509, doi: 10.1080/15362940802479920.

8. MICHAEL CLEMENS, CINDY HUANG, JIMMY GRAHAM, KATE GOUGH, A book: Migration is what you make it, Central Global Development, May 2018.

9. Pia M. Orrenius, Madeline Zavodny, Creating Cohesive, Coherent Immigration Policy, Journal of migration and human security, Volume 5 Number 1, PP:180-193, 2017.

10. Alice Szczepanikova, Tine Van Criekinge, The Future of Migration in the European Union, European Commission's Joint Research Centre, European Union, 2018.

11. Julia Tallmeister, Immigration a Threat to Security, E-International Relations, SSN 2053-8626, pp: 1-8, 24 August 2013.

12. Israt Jahan, Kangkhita Keam Psyche and Mithun Dutta, An Off-line E-Cash Scheme based on Group Blind Signature Scheme, International Journal of Engineering Research and Development, Volume 12, Issue 8, August 2016, PP.46-53, e-ISSN: 2278-067X, p-ISSN: 2278-800X. 